\title{
Central sympathetic blockade ameliorates brain death- induced cardiotoxicity and associated changes in myocardial gene expression
}

\author{
Thomas Yeh, Jr, MD, $\mathrm{PhD}^{\mathrm{a}}$ \\ Andrew S. Wechsler, MD ${ }^{\mathrm{C}}$ \\ Laura Graham, LVT ${ }^{\mathrm{e}}$ \\ Kathryn E. Loesser, $\mathrm{PhD}^{\mathrm{d}}$ \\ Domenic A. Sica, MD \\ Luke Wolfe, MS ${ }^{\mathrm{e}}$ \\ Emma R. Jakoi, $\mathrm{PhD}^{\mathrm{b}}$
}

\begin{abstract}
From the Jewish Hospital Cardiovascular Research Center at University of Louisville, Department of Surgery, ${ }^{\text {a }}$ Division of Cardiothoracic Surgery, University of Louisville, Louisville, Ky, Department of Cell Biology, ${ }^{\mathrm{b}}$ Duke University, Durham, NC, Department of Cardiothoracic Surgery, ${ }^{c}$ MCP Hahnemann University, Philadelphia, Pa, Department of Biological Sciences, ${ }^{\mathrm{d}}$ Mary Washington College, Fredericksburg, Va, and Departments of Surgery and Medicine, ${ }^{\mathrm{f}}$ Medical College of Virginia, Richmond, Va.
\end{abstract}

Supported in part by grants from the United States Public Health Service (grant GM3529 [E.R.J.], the National Institutes of Health (grant HL26302 [ASW]), and the American Heart Association (grant AHA94010440 [ASW]).

Received for publication Aug 8, 2001; revisions requested Dec 11, 2001; revisions received Jan 28, 2002; accepted for publication Feb 4, 2002

Address for reprints: Thomas Yeh, Jr, MD, $\mathrm{PhD}$, Department of Surgery, Division of Cardiothoracic Surgery, University of Louisville, Jewish Hospital Cardiovascular Research Center, 201 Abraham Flexner Way, Suite 1200, Louisville, KY 40202.

J Thorac Cardiovasc Surg 2002;124:1087-98

Copyright $(\odot 2002$ by The American Association for Thoracic Surgery

$0022-5223 / 2002 \$ 35.00+0 \quad \mathbf{1 2 / 1 / 1 2 4 8 8 7}$

doi:10.1067/mtc.2002.124887

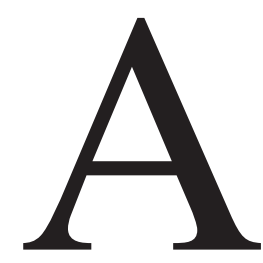

cute brain death caused by increased intracranial pressure (ICP) is associated with myocardial dysfunction and injury. ${ }^{1}$ As a result, $40 \%$ of potential donor hearts cannot be used. ${ }^{2}$ A subset of donor hearts that are accepted for donation will ultimately manifest early graft failure from the same phenomenon. Although the underlying molecular mechanisms remain undefined, the sympathetic nervous system has long been implicated in these changes.

After brain death, interstitial ${ }^{3}$ and systemic ${ }^{1}$ catecholamines are rapidly and markedly increased and then go on to decrease to levels below baseline. Fluctuations in catecholamine levels might act as important signals in the subsequent alterations in myocardial gene expression, ${ }^{1}$ specifically increases in cardiac and skeletal $\alpha$-ac- 
TABLE 1. Experimental groups

\begin{tabular}{lll}
\hline $\begin{array}{l}\text { Group } \\
\text { abbreviation }\end{array}$ & \multicolumn{1}{c}{ Group description } & $\begin{array}{c}\text { No. of } \\
\text { animals }\end{array}$ \\
\hline ICP-CSB & Brain death (increased intracranial pressure) with central sympathetic blockade & $\mathrm{n}=9$ \\
Sham-CSB & Sham-operated control animals with central sympathetic blockade & $\mathrm{n}=9$ \\
ICP & Brain death (increased intracranial-pressure) without central sympathetic blockade (previously published) ${ }^{1}$ & $\mathrm{n}=9$ \\
Sham & Sham-operated control animals without central sympathetic-blockade (previously published) & $\mathrm{n}=9$ \\
Naive & Unoperated controls animals used to establish baseline references at time 0 & $\mathrm{n}=6$ \\
\hline
\end{tabular}

TABLE 2. Quantitative scoring of left ventricular histologic injury

\begin{tabular}{|c|c|c|c|c|c|c|}
\hline \multirow[b]{2}{*}{ Histologic parameter } & \multicolumn{2}{|c|}{ No CSB } & \multirow{2}{*}{$\begin{array}{l}\text { Other comparisons } \\
\text { (1) vs (3) }\end{array}$} & \multicolumn{2}{|c|}{ CSB } & \multirow{2}{*}{$\begin{array}{l}\text { Other comparisons } \\
\text { (2) vs (4) }\end{array}$} \\
\hline & Sham (1) & ICP (2) & & Sham (3) & ICP (4) & \\
\hline Chromatin clumping & $0.000 \pm 0.000$ & $0.108 \pm 0.054^{*}$ & & $0.000 \pm 0.000$ & $0.000 \pm 0.000$ & * \\
\hline Contraction banding & $0.070 \pm 0.027$ & $0.354 \pm 0.067^{*}$ & * & $0.136 \pm 0.047$ & $0.058 \pm 0.025^{*}$ & * \\
\hline Cytoplasmic clearing & $0.837 \pm 0.062$ & $1.369 \pm 0.060^{*}$ & * & $0.375 \pm 0.059$ & $0.267 \pm 0.051^{*}$ & $*$ \\
\hline Loss of striations & $1.131 \pm 0.068$ & $1.582 \pm 0.055^{*}$ & $*$ & $0.378 \pm 0.060$ & $0.907 \pm 0.048^{*}$ & 0 \\
\hline
\end{tabular}

Four groups were examined: increased ICP and sham-operated (control) hearts in the absence of CSB (columns labeled 1 and 2, data previously reported) and in the presence of CSB (sham [column 3] and ICP-CSB [column 4]). Specimens were graded on a scale from 0 (no injury) to 2 (diffuse injury). Three sections from each animal were divided into 8 regions, resulting in 24 samplings from each animal. The increased ICP-CSB group shows some histologic injury when compared with sham-operated CSB animals but considerably less than in unattenuated animals with ICP. However, CSB abrogated much of the ICP-induced damage by all tested parameters. Data are reported as means \pm SEM.

*Significant differences between groups was determined by using analysis of variance, $P<.05$.

tin, egr-1, and heat shock protein 70 (hsp70). Catecholamines affect myocardial gene expression in cultured myocytes $^{4-7}$ and in clinical scenarios of congestive heart failure 8,9 and pheochromocytoma. ${ }^{10}$ In models of chronic catecholamine increase, decreased expression of mRNAs encoding sarcoplasmic reticulum proteins (calcium adenosine triphosphatase [ATPase], phospholamban, and calcium release channel) and myofibrillar proteins ( $\beta$ myosin heavy chain and $\alpha$-actin) is found, as is increased expression of atrial natriuretic factor messenger RNA. ${ }^{11}$ Increased levels of norepinephrine have also been shown to stimulate apoptosis. $^{12}$ In contrast, physiologic catecholamine release can initiate a growth (hypertrophic) response, including increased expression of mRNAs for myofibrillar proteins ${ }^{4,13,14}$ and transcription factors. ${ }^{15}$

The onset of cardiac dysfunction can be delayed 24 to 48 hours after head injury. This delay might be the result of a finite period of time required for changes in myocardial gene expression to be functionally manifest as decreased organ function. Earlier work supports this hypothesis, wherein brain death lead to increased expression of stressrelated and myofibrillar genes in a pattern that was similar to that for cardiac hypertrophy. ${ }^{1}$ In the current study pharmacologic blockade of the central sympathetic nervous system was used to test the hypothesis that sympathetic blockade would protect the heart during head injury and that this protection would prevent the increases in gene expression previously observed. ${ }^{1}$

\section{Methods}

\section{Anesthetic Regimens}

All experimental animals received humane care in compliance with the "Principles of Laboratory Animal Care" (National Society for Medical Research) and the "Guide for Care and Use of Laboratory Animals" (prepared by the Institute of Laboratory Animal Resources, National Research Council, and published by the National Academy Press, revised 1996). To minimize stress, animals were cared for in a controlled environment before experimentation. New Zealand White rabbits (3.5-4.0 kg) were used. Anesthesia was induced with fentanyl $(0.1 \mathrm{mg} / \mathrm{kg}$ administered intramuscularly) and maintained with inhaled isoflurane (3\% on induction and $1.5 \%$ after induction).

\section{Surgical Model}

A total of 42 New Zealand White rabbits were used. Surgical instrumentation was performed as previously described. ${ }^{1}$ After tracheostomy, ventilator adjustments were based on serial arterial blood gas measurements. Pulse and blood pressure from a carotid arterial line were recorded at baseline and at timed intervals over 4 hours. Electrocardiographic (ECG) recordings were taken before and after brain death. Rabbits were randomly assigned to the groups outlined in Table 1.

Results from the ICP and sham groups were previously published ${ }^{1}$ and are included here to facilitate comparisons. The current data were generated concurrently with the previously published data. Central sympathetic blockade (CSB) was achieved with 3 agents: xylazine, an $\alpha_{2}$-adrenergic agonist that blocks central sympathetic outflow ${ }^{16}$; acetylpromazine, which blocks peripheral $\alpha_{1^{-}}$ adrenergic receptors and central dopaminergic receptors ${ }^{17}$; and 
ketamine, an $N$-methyl-D-aspartate agonist that decreases plasma epinephrine and norepinephrine levels. ${ }^{18}$

After anesthesia was induced, a 5-mm burr hole was placed in the right parietal calvarium and an $8 \mathrm{~F}$ balloon-tipped catheter was inserted between the dura and calvarium. The balloon was rapidly inflated with $3 \mathrm{~mL}$ of saline solution to increase ICP $(t=0)$. Brain death occurred within 5 minutes of balloon inflation, as determined by means of electroencephalography. All operated groups were killed at 1,2 , and 4 hours. Naive rabbits $(n=6)$ were killed at time 0 to establish baseline controls. Hearts were rapidly excised and rinsed with cold heparinized saline solution, and the right and left ventricles were dissected. Myocardial tissue was frozen in liquid nitrogen and stored at $-70^{\circ} \mathrm{C}$.

\section{Histologic Evaluation}

Separate groups of operated hearts (ICP, ICP-CSB, sham-operated, and sham-operated CSB groups) were evaluated for cellular damage, as previously described. ${ }^{1}$ Ventricular tissue was divided into cross-sections $(2 \mathrm{~mm})$ and postfixed in $3 \%$ glutaraldehyde and $1.5 \%$ paraformaldehyde for 1 hour $\left(21^{\circ} \mathrm{C}\right)$ and then overnight $\left(4^{\circ} \mathrm{C}\right)$. Specimens were dehydrated, embedded in paraffin blocks, and sectioned. Three $7-\mu \mathrm{m}$ sections (taken from separate blocks) were stained with hematoxylin and eosin.

Sections were scored by a cardiac pathologist blinded to the experimental group by using a glass template to identify 8 regions per section. Each region was evaluated for 4 characteristics: contraction banding, myocytolysis, pyknotic nuclei, and loss of myofibrillar striations. A score of 0 indicated no damage. A score of 2.0 indicated widespread lesions. Intermediate lesions received scores ranging from 0.5 to 1.5 .

\section{RNA Analysis}

Total RNA was isolated by using a guanidinium isothiocyanate/ $\mathrm{CsCl} .{ }^{19}$ The integrity of mRNA and appropriate hybridization and wash stringencies were confirmed by means of Northern blot analyses, as previously described. ${ }^{1}$ Slot-blot hybridization was used to quantitate levels of specific mRNAs. Four micrograms of total RNA from each specimen was immobilized on a nitrocellulose membrane. Membranes were prehybridized $\left(42^{\circ} \mathrm{C}\right.$ overnight) in hybridization buffer $(4 \times$ standard saline citrate solution, 50 $\mathrm{mmol} / \mathrm{L} \mathrm{NaH} \mathrm{PO}_{4}, 0.2 \%$ sodium dodecylsulfate, $5 \times$ Denhardt's solution, $200 \mathrm{mg} / \mathrm{mL}$ tRNA, and $50 \%$ formamide) and then sequentially hybridized with a series of specific complementary phosphorus 32-labeled probes. Between probings, membranes were stripped $\left(80^{\circ} \mathrm{C}\right.$ for 2 minutes) and exposed to film overnight to verify the absence of signal.

Oligonucleotide probes were radiolabeled with T4 polynucleotide kinase reaction. Complementary DNA probes were radiolabeled with random primers and Klenow polymerase. Total poly(A)+RNA was estimated by hybridization with poly $\mathrm{d}(\mathrm{T})$ probe (BD Biosciences Clontech, Palo Alto, Calif).

\section{Densitometry and Data Standardization}

Hybridization signals were quantitated by means of densitometric scanning of autoradiograms exposed within the linear range of the $\mathrm{x}$-ray film. Integrated densities of each specimen were calculated with the GELScan 1D analysis program (Pharmacia LKB, Piscataway, NJ). The optical density was normalized to that of
poly(A) + RNA to adjust for variations in loading and transfer. The mean of this ratio was then divided by the mean of naive hearts $(\mathrm{t}=0)$ and plotted against time. Data are reported as means \pm SEM.

\section{Quantitation of Systemic Catecholamines}

Plasma epinephrine and norepinephrine levels were measured before and serially after balloon inflation, as previously described. ${ }^{1}$ Levels were determined with an ESA Coulochem II Electrochemical Detector; ESA, Inc, Chelmsford, Mass). Plasma catecholamines were extracted with aluminum oxide and separated by means of high-pressure liquid chromatography with an isocratic mobile phase $\left(85 \% \mathrm{NaH}_{2} \mathrm{PO}_{4}\right.$ and $15 \%$ acetonitrile, adjusted to $\mathrm{pH}$ 3.0 with $\mathrm{H}_{3} \mathrm{PO}_{4}$ ). Run time was 28 minutes. The limit of detection was $10 \mathrm{pg} / \mathrm{mL}$.

\section{Statistical Analyses}

Statistical analyses were performed with SAS software (SAS Institute, Inc, Cary, NC). Analysis of variance was used to determine the significance of change at each time point between groups and changes over time within each group.

\section{Results}

Sympathetic Blockade Improves the Hemodynamic Instability Associated With Brain Death

In the presence of sympathetic blockade, brain death resulted in a slight but significant increase in heart rate within 30 minutes (Figure 1, A). This relatively small increase in heart rate gradually settled over 4 hours to a level significantly below baseline. This is in distinct contrast to brain death in the absence of sympathetic blockade (Figure 1, B). These animals exhibited marked tachycardia 1 to 5 minutes after brain death. No significant difference in heart rate was observed in either sham-operated group, although the baseline heart rate was lower in the sham-operated group with CSB. Of note, the bradycardia one might expect as part of the Cushing response is typically present when ICP is increased more slowly. Tachycardia results in this model because of the rapidity with which ICP was increased.

In the presence of sympathetic blockade, brain death resulted in no hypertensive response and less hemodynamic deterioration by 4 hours (Figure 1,C). Again, in distinct contrast, unattenuated brain death resulted in a marked hypertensive response and a significant hypotensive response at 30 minutes (Figure 1,D). The sham-operated control groups showed a slow decline in mean arterial pressure over time.

\section{Sympathetic Blockade Prevents EGG Changes Associated With Brain Death}

As previously reported, ${ }^{1}$ after brain death, analysis of ECG ST segments previously revealed abnormal ST segments (ST-segment depression, ST-segment elevation, or T-wave inversion) in all animals undergoing unattenuated increases in ICP. In contrast, sympathetic blockade preserved normal 

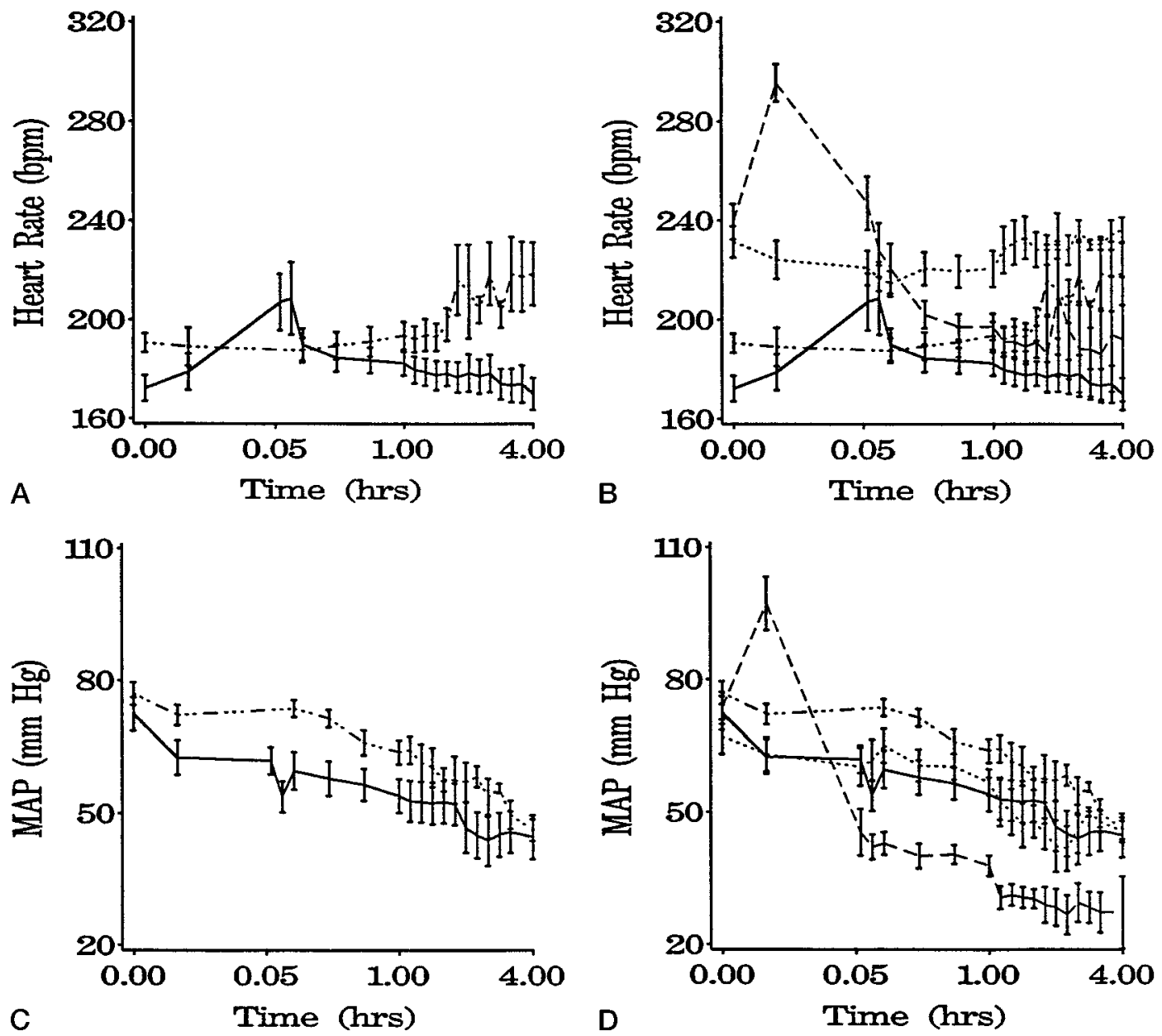

Figure 1. Effects of sympathetic blockade on hemodynamic changes (in heart rate and mean arterial pressure [MAP] induced by brain death resulting from increased ICP. Data are reported as means \pm SEM. Asterisks denote a significant $\boldsymbol{P}$ value. Table 1 summarizes the experimental groups and legends for these graphs: solid line, ICP-CSB group; dashed and dotted line, sham-CSB group; dashed line, ICP group; dotted line, sham group. A, Heart rates during sympathetic blockade (ICP-CSB and sham-CSB groups). Note the relative absence of tachycardia in either group during sympathetic blockade. Differences between groups are significant $(P<.05)$ at time points 0 and 2 through 4 hours. Within the ICP-CSB group, significant differences from baseline over time were found at time points $0.08,0.17$, and 0.24 hours. Within the sham-operated group, changes over time were significant at time points 3.00, 3.50, 3.75, and 4.00 hours. B, Heart rates during sympathetic blockade (ICP-CSB and sham-CSB groups, see above) are compared with heart rates without sympathetic blockade (ICP and sham groups, as previously reported ${ }^{1}$ ). Note the tachycardia induced during brain death without sympathetic blockade (ICP group). Note also the relatively lower heart rates present in both groups undergoing sympathetic blockade (ICP-CSB and sham-CSB groups), affirming the adequacy of sympathetic blockade in those animals. Finally, note the similarly low heart rate achieved after brain death without sympathetic blockade (ICP group). C, Temporal profile of mean arterial pressure for ICP-CSB and sham-CSB animals. Note the absence of hypertension induced by means of CSB. Differences between groups are significant $(P<.05)$ at time points 0.25 to 1 hour. Within the ICP-CSB group, significant difference from baseline over time were found at all time points except 0.02 to 0.17 hours. Within the shamoperated group, changes over time were significant at all time points from 0.75 to 4.00 hours. D, Comparison of above data with increases in mean arterial pressures previously reported for increased ICP (ICP group) and sham-operated animals (sham) without sympathetic blockade. Note that ICP without sympathetic blockade results in more hemodynamic instability than ICP protected by sympathetic blockade. 
Before Intervention

Sham

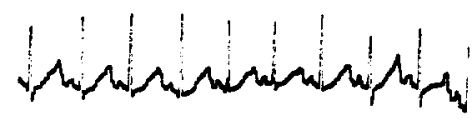

$\uparrow$ ICP

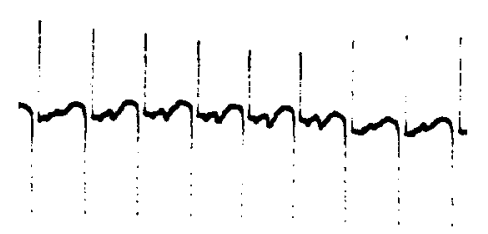

† ICP

CSB

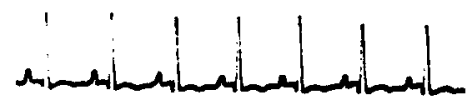

After Intervention
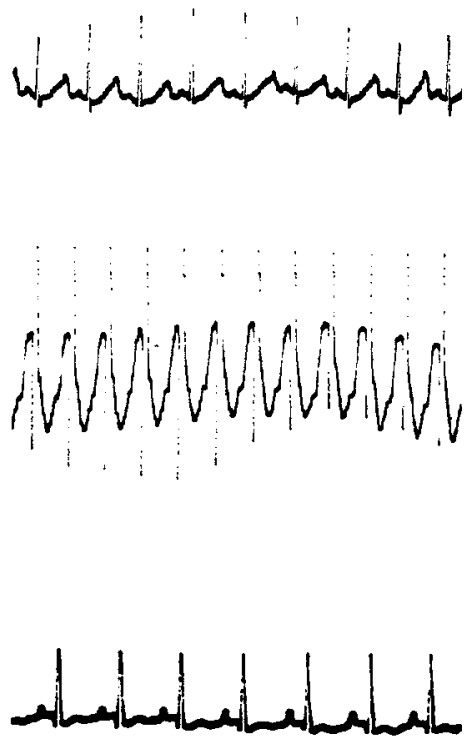

Figure 2. Effects of CSB on increased ICP-induced changes in electrocardiograms. Sham-operated animals showed no change before and after intervention. Brain dead animals without CSB (ICP) revealed abnormal ST-segment morphology that persisted variably over the course of the experiment. Brain dead animals with CSB (ICP-CSB) revealed no change in ECG morphology before or after brain death.

ECG morphology (Figure 2). Sham-operated control animals were also unchanged over time (2-4 hours).

\section{Sympathetic Blockade Prevents the Catecholamine Surge Induced by Brain Death}

Plasma epinephrine and norepinephrine levels were measured after brain death with and without sympathetic blockade to verify that sympathetic blockade was effective. The brain dead and sham-operated control groups with sympathetic blockade (ICP-CSB and sham-CSB groups) did not differ in plasma epinephrine or norepinephrine levels (Figure $3, A$ and $C$, respectively). When sympathetically blocked animals were compared with sham-operated animals without sympathetic blockade (Figure $3, B$ and $D$, respectively), catecholamine levels were significantly lower than baseline levels. Fifteen minutes after balloon inflation, the ICP-CSB group had similarly low plasma epinephrine and norepinephrine levels of $13 \mathrm{pg} / \mathrm{mL}$ (Figure 3, A) and 56 $\mathrm{pg} / \mathrm{mL}$ (Figure 3,C), respectively.

In contrast, 15 minutes after balloon inflation, the ICP group (without sympathetic blockade) showed a 3.5-fold increase in plasma epinephrine $(772 \mathrm{pg} / \mathrm{mL}$; Figure 3, B) and an 8-fold increase in plasma norepinephrine (3042 $\mathrm{pg} / \mathrm{mL}$; Figure 3, D) levels. A significant decline in plasma catecholamine levels were found 2 to 4 hours after balloon inflation in the ICP group (Figure 3, $B$ and $D$ ). Plasma catecholamine levels in the sham-operated (control) group remained unchanged over time (Figure 3, $B$ and $D$ ). This decrease in catecholamine levels in animals with increased ICP temporally corresponded to a decline in mean arterial pressure and heart rate. After unattenuated brain death, catecholamine levels decreased to levels that were similar to those observed in the presence of sympathetic blockade.

\section{Sympathetic Blockade Prevents the Histologic Injury} Associated With Brain Death

Sixty minutes after brain death, hearts from 2 rabbits in each group (ICP-CSB, sham-operated CSP, ICP, ${ }^{1}$ and shamoperated ${ }^{1}$ groups) were fixed, stained, and then graded by a cardiac pathologist blinded to experimental group. Representative sections are shown in Figure 4. Hearts were individually graded for changes in 4 parameters by using a score that ranged from 0 (no injury) to 2 (diffuse injury). As reported previously, ${ }^{1}$ the brain death (ICP) group exhibited significantly more cellular injury, as evidenced by cytoplasmic clearing, loss of myofibrillar striations, and contraction banding; however, no interstitial mononuclear cell infiltration and few pyknotic nuclei were seen. In contrast, these experiments reveal that brain death, in the presence of 

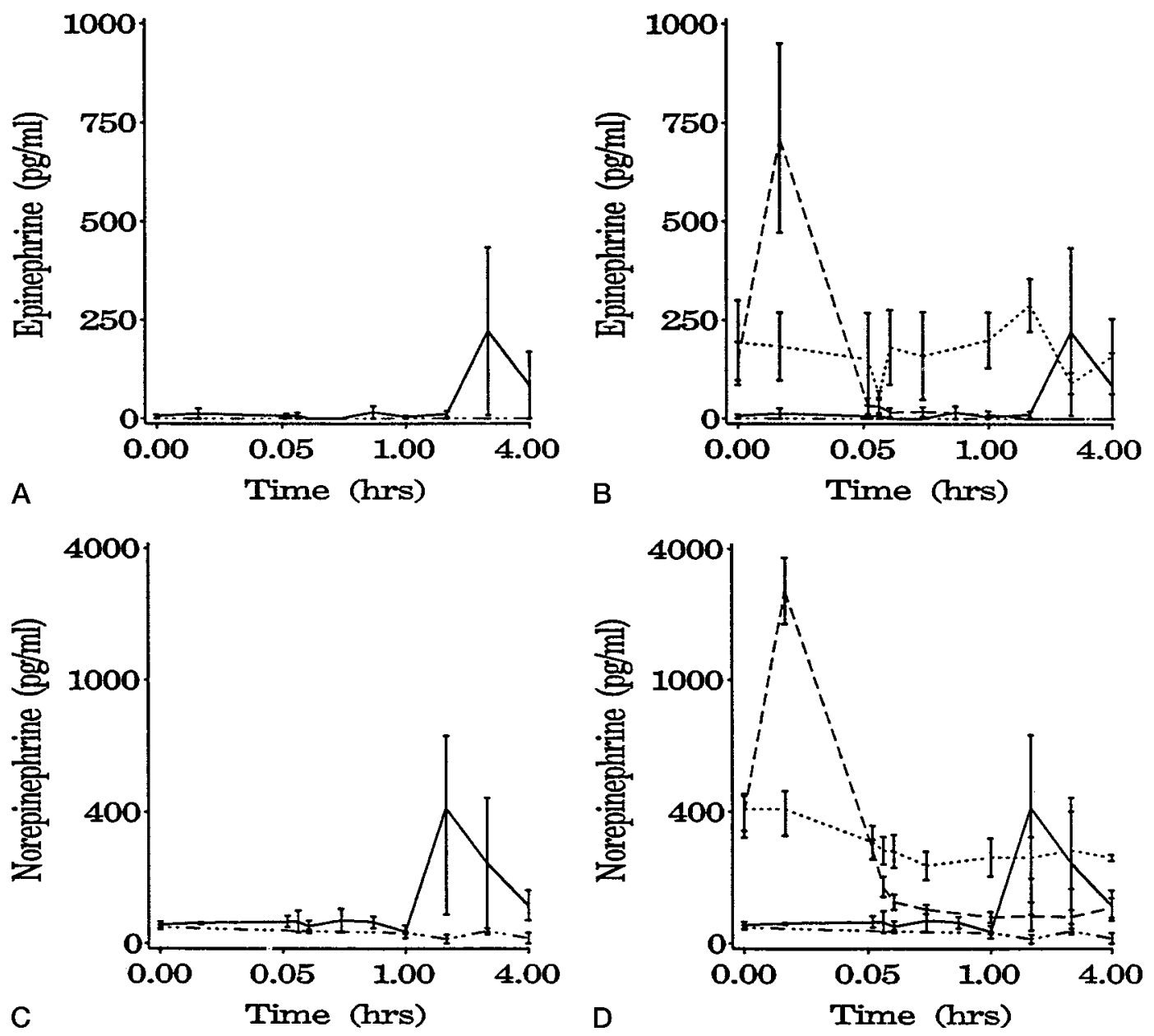

Figure 3. Effects of CSB on increased ICP-induced changes in systemic catecholamine (epinephrine and norepinephrine) levels. Data are given as means \pm SEM. Asterisks denote a significant $\boldsymbol{P}$ value. Table 2 summarizes the experimental groups and legends for these graphs: solid line, ICP-CSB group; dashed and dotted line, sham-CSB group; dashed line, ICP group; dotted line, sham group. A, Temporal profile of systemic epinephrine levels for ICP-CSB and sham-CSB animals. Note the stable and low epinephrine levels induced by means of CSB. Differences between groups are not significant at any time point. Within the ICP-CSB group, no significant difference from baseline was noted over time. Within the sham-operated group, changes over time were not significant at any time point. B, Comparison of above data with increases in systemic epinephrine levels previously reported for ICP and sham-operated animals without blockade. Note that baseline levels are much lower in animals with sympathetic blockade. C, Temporal profile of systemic norepinephrine levels for ICP-CSB and sham-CSB animals. Note the stable and low norepinephrine levels induced by CSB. Differences between groups are not significant at any time point. Within the ICP-CSB group, no significant difference from baseline was noted over time. Within the sham-operated group, changes over time were significant at 2 hours. D, Comparison of above data with increases in systemic norepinephrine levels previously reported for increased ICP and sham-operated animals without blockade. Note that baseline levels are much lower in animals with sympathetic blockade.

sympathetic blockade (Table 2), resulted in significantly less injury than that seen in the brain dead group (but more than that seen in the CSB sham-operated group).

Sympathetic Blockade Neutralized the Increases in Myocardial Gene Expression Induced by Brain Death

Levels of mRNAs encoding myofilament proteins. The mRNA expression levels of cardiac $\alpha$-actin (Figure 5, A) and skeletal $\alpha$-actin (Figure 5, B) were assayed in the ICP-CSB group and compared with that in the ICP group and that in naive animals. Four hours after balloon inflation, significant $(P<.05)$ decreases were noted in the ICP-CSB group. Relative expression levels for these mRNAs decreased 2-fold in the ICP-CSB group.

When $\alpha$ myosin heavy chain (MHC; Figure 5,C) and $\beta$-MHC (Figure 5, D) mRNA levels were examined, the 


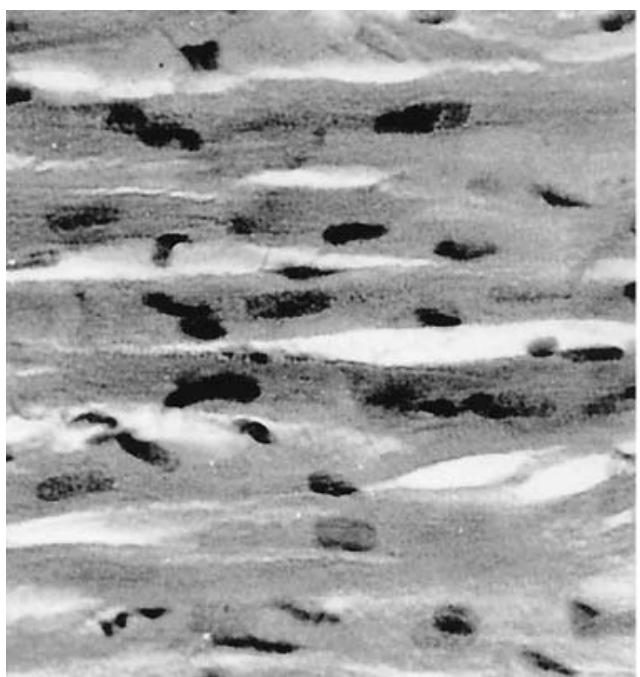

Sham Operated Control

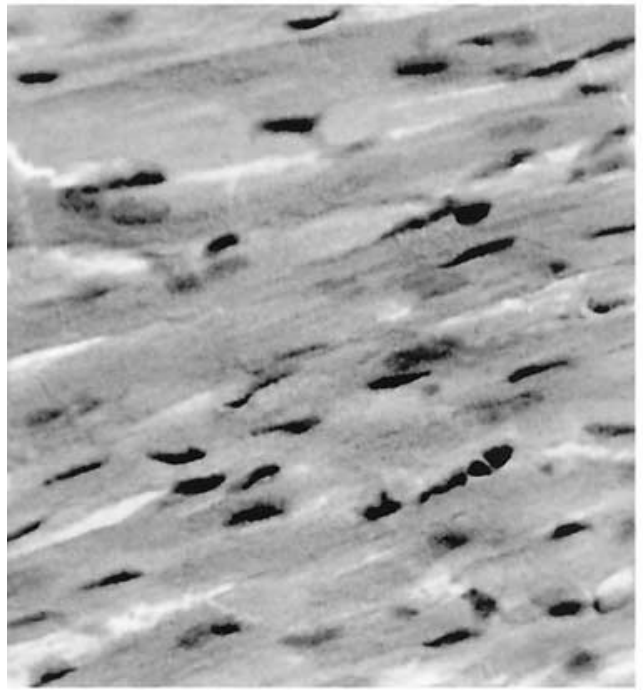

Sham Operated Control-CSB

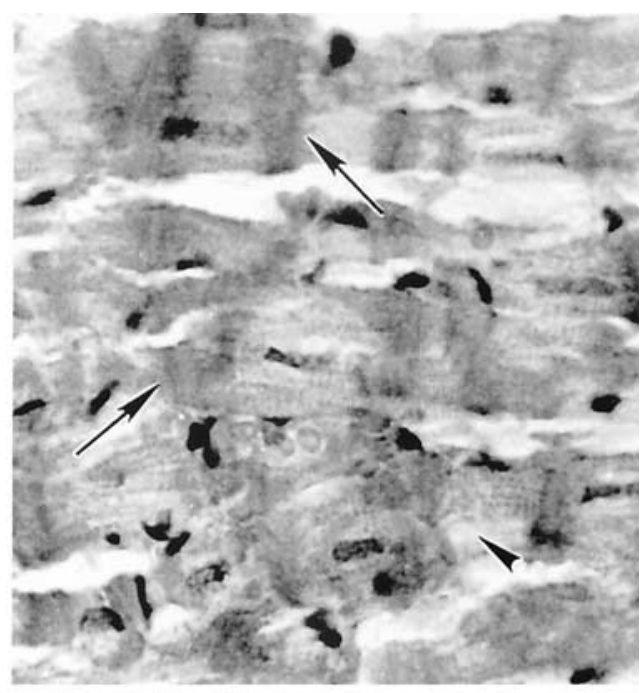

$\uparrow$ ICP

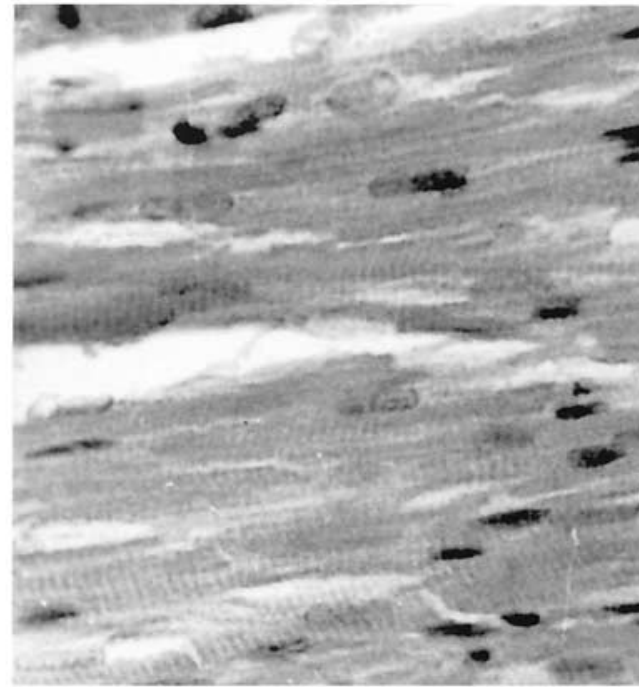

ICP-CSB

Figure 4. Effect of increased ICP on left ventricular myocardial histologic features. Representative light micrographs of the left ventricle are shown 60 minutes after burr hole placement in sham-operated control animals versus brain death (ICP). Increased ICP resulted in pronounced contraction band necrosis and myocytolysis. In contrast, brain death ameliorated with CSB (ICP-CSB) abrogates these effects with sparse lesions and minimal contraction banding. Sham-operated control animals in the presence of CSB are shown for the sake of completeness. (Hematoxylin and eosin stain, original magnification $300 \times$.)

ICP-CSB group failed to show the significant and sustained (1-4 hours) increase observed after ICP. In the presence of sympathetic blockade, levels of mRNA encoding $\alpha$-MHC (Figure 5, $C$ ) were significantly 6-fold lower than those of ICP animals and were one half those of naive levels at 1,2 , and 4 hours. Similarly, ICP-CSB animals failed to show the increase in $\beta$-MHC mRNA manifested by ICP animals
(Figure $5, D$ ), and by 4 hours, levels were significantly lower than those in the ICP group.

Levels of mRNAs encoding adrenergic receptors. With increased ICP, no significant difference in mRNAs encoding $\alpha_{1^{-}}$(Figure 5, $E$ ) or $\beta_{1}$-adrenergic (Figure 5, $F$ ) receptors were found at 4 hours, although $\beta_{1}$-adrenergic receptor was transiently decreased in the ICP-CSB group. 
A

IV cantiax actin

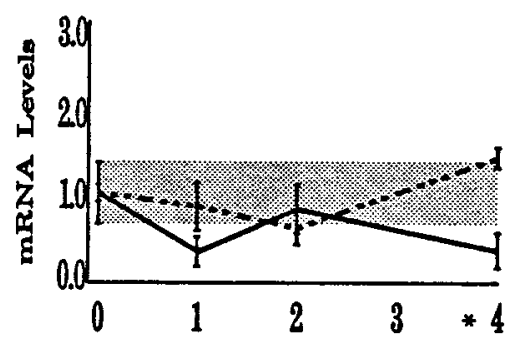

B

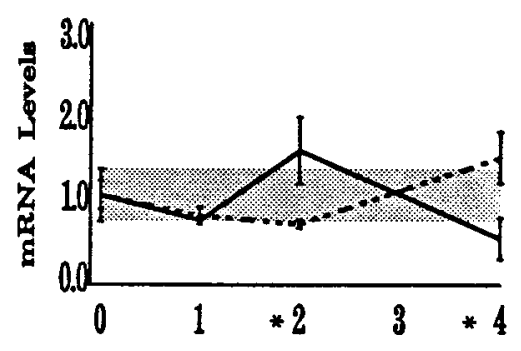

C

LV appha MHC

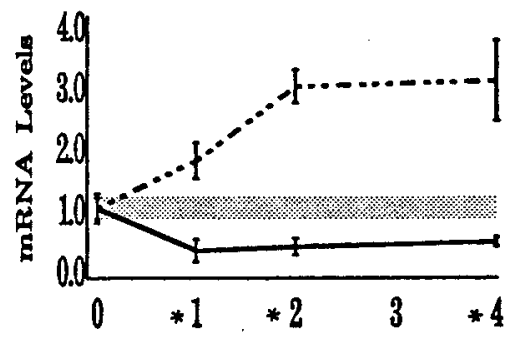

D

LV beta MHC

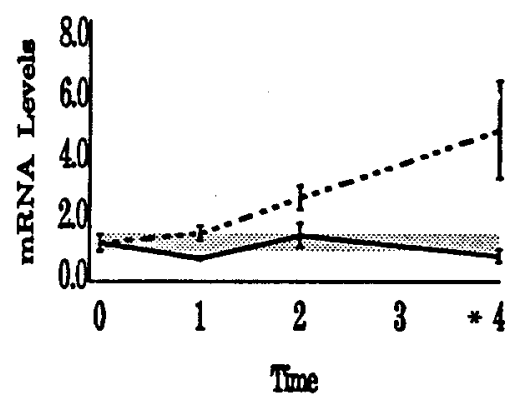

E

LV aphal AR

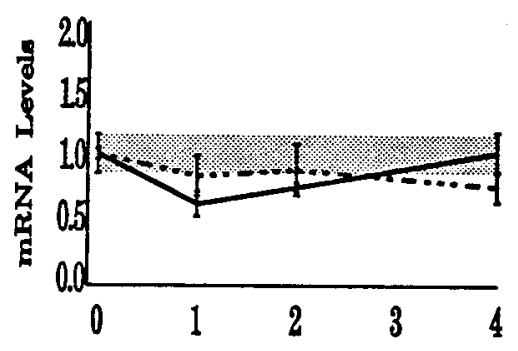

F

IV betal AR

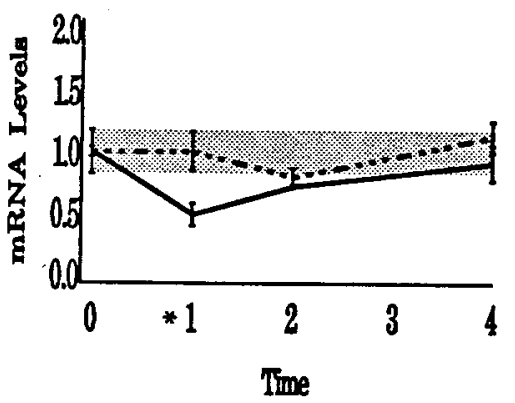

Figure 5. Temporal profile of specific mRNA expression levels in response to CSB in concert with increased ICP. A through $M$ show levels of specific mRNAs (as a ratio of poly $(A)+R N A$ in that same specimen). Data are reported as means \pm SEM. Time (in hours) is shown on the $x$ axis. Time point 0 depicts steady state mRNA levels of naive hearts. The SEM of this group is extended horizontally across the graph as a baseline reference (shaded bar). Asterisks indicate a statistically significant difference between groups at a given time point $(P<.05$, analysis of variance). Animals with increased ICP are denoted by the dashed line, and ICP-CSB animals are denoted by the solid line. See text for description of specific mRNA levels and Table 3 for a summary of changes. 
G

IV CA NIPase

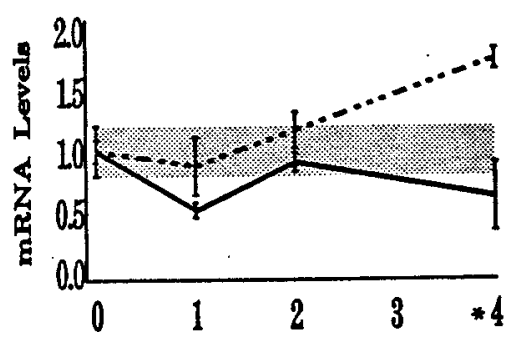

H
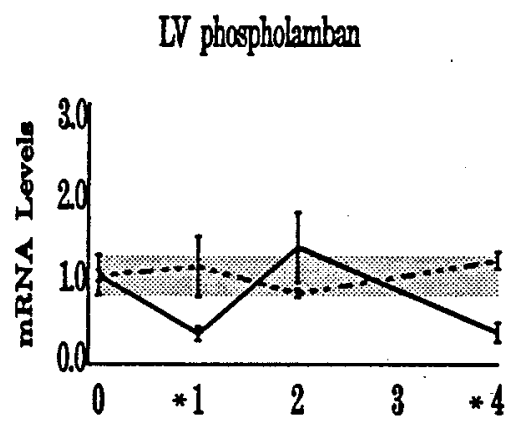

I
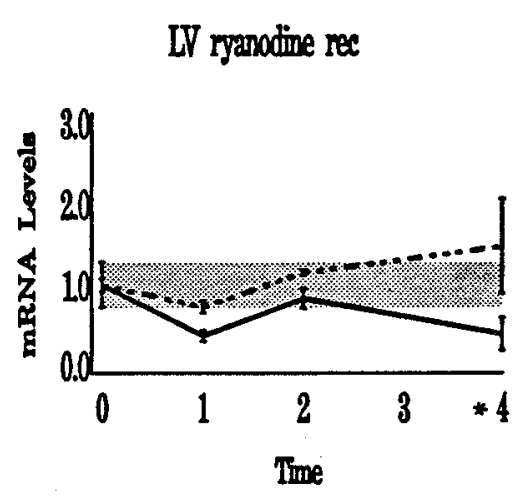

$\mathbf{J}$

LV e-fos

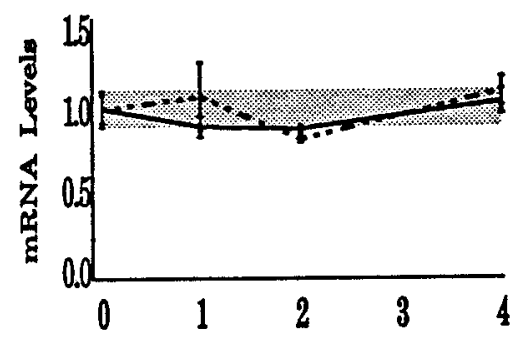

$\mathbf{K}$
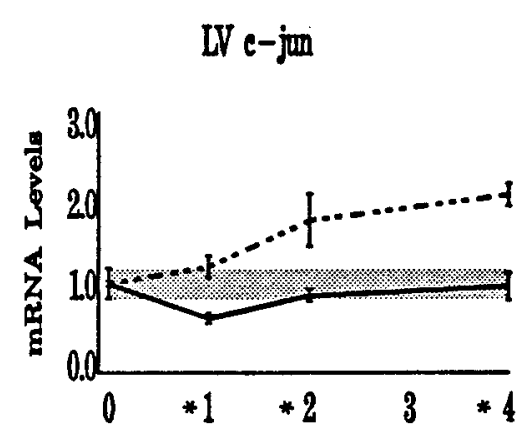

$\mathbf{L}$

LV e-egr

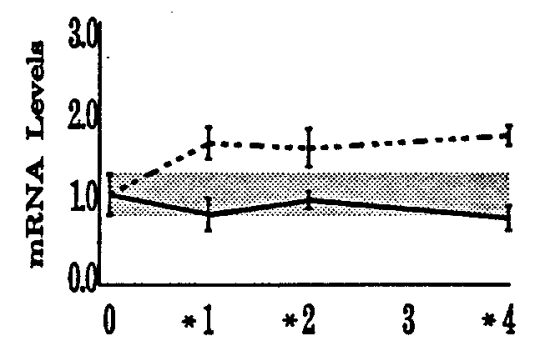

M

\section{LV hspplo}

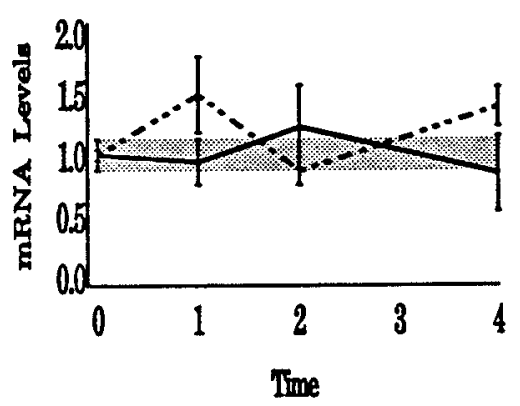

Figure 5. Cont'd.

Levels of mRNAs encoding sarcoplasmic reticulum proteins. When the expression levels for mRNAs encoding sarcoplasmic reticulum proteins were measured in ICP-CSB hearts, by 4 hours, significant decreases in mRNAs encoding calcium ATPase (SERCA-2a; Figure 5, G), phospho- lamban (Figure 5, $H$ ), and the calcium release channel or ryanodine receptor (Figure 5, I) were noted relative to the ICP group.

Levels of mRNAs encoding immediate early genes and cellular stress-response genes. Blots were sequentially hy- 
TABLE 3. Comparison of the effect of increased ICP with that of ICP-CSB on myocardial gene expression

\begin{tabular}{|c|c|c|c|c|c|}
\hline \multicolumn{2}{|l|}{ mRNA group } & \multicolumn{4}{|c|}{$\begin{array}{c}\text { Panel } \\
\text { (from } \\
\text { Fiqure 5) }\end{array}$} \\
\hline \multirow[t]{4}{*}{ Myofilaments } & Myosin heavy chain & $\alpha \mathrm{MHC}$ & $A$ & $\sim$ & $\downarrow$ \\
\hline & & $\beta \mathrm{MHC}$ & $\mathrm{B}$ & $\sim$ & $\downarrow$ \\
\hline & $\alpha$ Actins & Cardiac $\alpha$-actin & C & $\uparrow$ & $\downarrow$ \\
\hline & & Skeletal $\alpha$-actin & D & $\uparrow$ & $\downarrow$ \\
\hline \multirow{2}{*}{\multicolumn{2}{|c|}{ Adrenergic receptors }} & $\alpha 1$ adrenergic receptor & $\mathrm{E}$ & $\sim$ & $\sim$ \\
\hline & & $\beta 1$ adrenergic receptor & $\mathrm{F}$ & $\sim$ & $\mathrm{T} \downarrow$ \\
\hline \multirow{3}{*}{\multicolumn{2}{|c|}{ Sarcoplasmic reticulum proteins }} & CaATPase (Serca 2a) & G & $\sim$ & $\downarrow$ \\
\hline & & Phospholamban (Plb) & $\mathrm{H}$ & $\sim$ & $\downarrow$ \\
\hline & & Ryanodine receptor (RyR) & I & $\sim$ & $\downarrow$ \\
\hline \multirow{3}{*}{\multicolumn{2}{|c|}{ Immediate early genes }} & c-fos & J & $\sim$ & $\sim$ \\
\hline & & c-jun & K & $\sim$ & $\downarrow$ \\
\hline & & egr-1 & L & $\uparrow$ & $\downarrow$ \\
\hline \multicolumn{2}{|c|}{ Heat shock protein 70} & hsp 70 & $\mathrm{M}$ & $\uparrow$ & $\sim$ \\
\hline
\end{tabular}

Specific mRNAs are evaluated as indicated. The direction of change in gene expression is depicted: $\uparrow$, direction of change is increased $(P<.05)$; $\downarrow$, direction of change is decreased $(P<.05) ; \sim$, there is no significant change; and $T$, change is transient. $L V$, Left ventricular.

bridized with c-fos (Figure 5, J), c-jun (Figure 5, K), egr-1 (Figure $5, L$ ), and hsp70 (Figure 5, $M$ ) cDNA probes. When mRNA levels in ICP-CSB hearts were compared with those of the ICP group, significantly lower egr-1 (Figure $5, L$ ) and c-jun (Figure 5, $K$ ) mRNA levels were found at 1, 2, and 4 hours. In the ICP group each mRNA had accumulated 2-fold over time (1-4 hours), whereas levels in the ICP-CSB group did not differ from those of the naive animals (Figure $5, K$ and $L$ ). mRNA levels for c-fos (Figure 5, $J$ ) and hsp70 (Figure $5, M$ ) were not significantly different in the ICPCSB group compared with those of ICP and naive animals.

\section{Discussion}

Previous studies have implicated the neuromyocardial axis in the impaired cardiac function observed in brain dead donors. ${ }^{20-23}$ In the current study pharmacologic blockade of sympathetic outflow blunted the early pressor response, electrocardiographic ST-segment changes, the early (1minute) spike in plasma catecholamines, and myocardial injury associated with ICP-induced brain death. Sympathetic blockade also eliminated the brain death-associated increases in expression of myocardial gene products that govern contractility and growth, significantly lowering the expression levels of multiple and specific mRNAs in the left ventricle (Table 3 ). These decreases were noted in all tested myofilament programs ( $\alpha$-actins and MHCs), all of the sarcoplasmic reticulum genes (calcium ATPase [SERCA2a], calcium release channel [ryanodine receptor], and phospholamban), and the transcription factors c-jun and egr- 1 . The novel data in these experiments are that myocardial gene expression changes after brain death, and adrenergic blockade interrupts those changes. Although it would be tempting to claim that a single gene is responsible, the interaction of myocardial genes in complex, overlapping, and redundant signaling networks makes this possibility unlikely. By studying a panel of genes, we hoped to shed light on more global patterns of gene expression after brain death.

Decreases in sympathetic activity observed in this model of sympathetic blockade but also manifesting in brain dead organ donors after the initial sympathetic surge are associated with significant decreases in expression of multiple and specific myocardial gene products. Collectively, these results correlate with previous studies in which catecholamines altered myocardial gene expression in models of injury and growth. Moreover, they suggest that loss of sympathetic tone might result in decreases in myocardial gene expression. Whether this is a direct effect of catecholamine withdrawal or a decrease in cardiac afterload resulting from decreased contractility, vascular resistance, or preload is not known. Decreased afterload has been reported in brain injury, but contractility might be depressed as well. Our data cannot discriminate between these hemodynamic factors. In the unloaded myocardium, transcriptional activity of myocardial genes and expression levels of mRNAs encoding proteins important for contractility are reduced. ${ }^{4,13,14,24,25}$ Moreover, specific isoforms of proteins that are expressed recapitulate development and thereby alter the physiologic response of the heart. Like mechanical unloading, a decrease in either catecholamine or trophic factors can result in deprogramming and alter ventricular function both in adult and neonatal myocardium. ${ }^{26-29}$ In our study of ICP, the reduction in select mRNA levels correlates with decreased catecholamine levels, suggesting that ICP and ICP-CSB-treated hearts might ultimately manifest similar phenotypes as the ICP hearts move temporally further from the catecholamine spike induced by brain death.

The relationship between myocardial dysfunction and 
phenotype is clear in more chronic conditions, such as increased afterload or toxic exposures. Although we have not demonstrated cause and effect in these experiments, hemodynamic instability and alterations in myocardial gene expression are at least associated after brain death. Both are interrupted by blocking the adrenergic signaling cascade. We believe that the relationship between gene expression and myocardial dysfunction might be underappreciated in acute settings. For instance, it seems plausible that altered myocardial gene expression plays an important role in postoperative settings in which preoperative myocardial dysfunction is fatally exacerbated after the shock of global ischemia and cold cardioplegia.

In conclusion, brain death-associated increases in sympathetic nervous activity initiate changes in myocardial gene expression that might result in myocardial deprogramming and ventricular remodeling. The observed late decreases in systemic catecholamines associated with brain death are implicated in the suppression of myocardial gene expression. We hypothesize that these changes in gene expression might affect myocardial function, even after transplantation. Although we clearly show that both excess as well as depletion of systemic catecholamines are associated with altered myocardial gene expression and function, our data do not preclude other neurohumoral factors altered by ICP, such as decreases in systemic levels of insulin, ${ }^{30} \mathrm{~T} 3$ or $\mathrm{T} 4,{ }^{31}$ or antidiuretic hormone, ${ }^{32}$ as important contributing factors that define the ultimate phenotype of donor hearts. Although the biologic significance of altered myocardial gene expression after ICP-induced brain death is not yet understood, it is important to realize that catecholamineassociated donor myocardial dysfunction might be a result not so much of toxicity but rather of changes in myocardial gene expression. We are currently delineating these changes 48 hours after the insult of brain death to mirror a more typical time point when transplant physicians are faced with deciding whether donor heart dysfunction precludes safe transplantation.

We thank Dr D. Darling (University of Chicago) and Dr P. K. Umeda (University of Alabama) for the gifts of sequences encoding rabbit pMHC- $\alpha 812$ and $\mathrm{p} 251-1 \beta$-MHC, Dr L. Jones (University of Indiana) for pGEM3z-PLB7, Dr L. Kedes (University of Southern California) for LK295 (skeletal $\alpha$-actin) and LK300 (cardiac $\alpha$-actin), Dr T. Curran (Roche Institute) for pSp65-cfos, Dr R. J. Lefkowitz (Duke University) for pTZ18R $\alpha_{1}$-adrenergic receptor and pSP65 $\beta_{1}$-adrenergic receptor, and Dr V. Sukhatme for pUC13.191. Egr-1, pH2.3, and hsp70 were purchased from American Type Culture Collection, Manassas, Virginia.

\section{References}

1. Yeh TJ, Wechsler AS, Graham LJ, Loesser KE, Sica DA, Solfe L, et al. Acute brain death alters left ventricular myocardial gene expression. J Thorac Cardiovasc Surg. 1999;117:365-74.
2. Richards PS, Nelson KA, Frazier OH, Radovancevic B, Van Buren C, Young JB. Why referred potential heart donors aren't used. Tex Heart Inst J. 1993;20:218-22.

3. Mertes PM, Carteaux JP, Jaboin Y, et al. Estimation of myocardial interstitial norepinephrine release after brain death using cardiac microdialysis. Transplantation. 1994;57:371-7.

4. Bishopric NH, Simpson PC, Ordahl CP. Induction of the skeletal alpha-actin gene in alpha 1-adrenoceptor-mediated hypertrophy of rat cardiac myocytes. J Clin Invest. 1987;80:1194-9.

5. Simpson PC, Long CS, Waspe LE, Henrich CJ, Ordahl CP. Transcription of early developmental isogenes in cardiac myocyte hypertrophy. J Mol Cell Cardiol. 1989;21(Suppl 5):79-89.

6. Bishopric NH, Kedes L. Adrenergic regulation of the skeletal alphaactin gene promoter during myocardial cell hypertrophy. Proc Natl Acad Sci U S A. 1991;88:2132-6.

7. Gupta MP, Gupta M, Dizon E, Zak R. Sympathetic control of cardiac myosin heavy chain gene expression. Mol Cell Biochem. 1996;157: $117-24$.

8. Arai M, Alpert NR, MacLennan DH, Barton P, Periasamy M. Alterations in sarcoplasmic reticulum gene expression in human heart failure. A possible mechanism for alterations in systolic and diastolic properties of the failing myocardium. Circ Res. 1993;72:463-9.

9. Lai LP, Raju VS, Delehanty JM, Yatani A, Liang CS. Altered sarcoplasmic reticulum $\mathrm{Ca}^{2+}$ ATPase gene expression in congestive heart failure: effect of chronic norepinephrine infusion. $\mathrm{J} \mathrm{Mol} \mathrm{Cell} \mathrm{Cardiol.}$ 1998;30:175-85.

10. Jiang JP, Downing SE. Catecholamine cardiomyopathy: review and analysis of pathogenetic mechanisms. Yale J Biol Med. 1990;63:58191.

11. Lown B. Sudden cardiac death: the major challenge confronting contemporary cardiology. Am J Cardiol. 1979;43:313-28.

12. Communal C, Singh K, Pimentel DR, Colucci WS. Norepinephrine stimulates apoptosis in adult rat ventricular myocytes by activation of the beta-adrenergic pathway. Circulation. 1998;98:1329-34.

13. Meidell RS, Sen A, Henderson SA, Slahetka MF, Chien KR. Alpha 1 -adrenergic stimulation of rat myocardial cells increases protein synthesis. Am J Physiol. 1986;251:H1076-84

14. Simpson P. Stimulation of hypertrophy of cultured neonatal rat heart cells through an alpha 1-adrenergic receptor and induction of beating through an alpha 1- and beta 1-adrenergic receptor interaction. Evidence for independent regulation of growth and beating. Circ Res. 1985;56:884-94.

15. Simpson PC. Role of proto-oncogenes in myocardial hypertrophy. Am J Cardiol. 1988;62:13G-9G.

16. Brearley JC, Dobson H, Jones RS. Investigations into the effect of two sedatives on the stress response in cattle. $J$ Vet Pharmacol Ther. 1990;13:367-77.

17. Walker M, Geiser D. Effects of acetylpromazine on the hemodynamics of the equine metatarsal artery, as determined by two-dimensional real-time and pulsed Doppler ultrasonography. Am J Vet Res. 1986; 47:1075-8.

18. Hoffman WE, Pelligrino D, Werner C, Kochs E, Albrecht RF, Schulte AE. Ketamine decreases plasma catecholamines and improves outcome from incomplete cerebral ischemia in rats. Anesthesiology. 1992;76:755-62.

19. Maniatis T, Fritsch EF, Sambrook J. Extraction, purification, and analysis of mRNA from eukaryotic cells. In: Molecular cloning: a laboratory manual. New York: Cold Spring Harbor Laboratory Press; 1989. p. 7.19-7.22.

20. Bitter HB, Kendall SW, Campbell KA, Montine TJ, Van Trigt P. A valid experimental brain death organ donor model. J Heart Lung Transplant. 1995;14:308-17.

21. Heggtveit HA. The donor heart: brain death and pathological changes in the heart. Laval Med. 1970;41:178-9.

22. Novitzky D, Wicomb WN, Cooper DKC, Rose AG, Fraser RC, Barnard CN. Electrocardiographic, hemodynamic and endocrine changes occurring during experimental brain death in the chacma baboon. Heart Transplantation. 1984;4:63-9.

23. Novitzky D, Wicomb WN, Cooper DK, Rose AG, Reichart B. Prevention of myocardial injury during brain death by total cardiac 
sympathectomy in the Chacma baboon. Ann Thorac Surg. 1986;41: 520-4.

24. Schaub MC, Hefti MA, Harder BA, Eppenberger HM. Various hypertrophic stimuli induce distinct phenotypes in cardiomyocytes. $J$ Mol Med. 1997;75:901-20.

25. Knowlton KU, Baracchini E, Ross RS, et al. Co-regulation of the atrial natriuretic factor and cardiac myosin light chain-2 genes during alphaadrenergic stimulation of neonatal rat ventricular cells. Identification of cis sequences within an embryonic and a constitutive contractile protein gene which mediate inducible expression. J Biol Chem. 1991; 266:7759-68.

26. Fernandez-Alfonso MS, Ganten D, Paul M. Mechanisms of cardiac growth. The role of the renin-angiotensin system. Basic Res Cardiol. 1992;87(Suppl 2):173-81

27. Katzeff HL, Ojamaa KM, Klein I. Effects of exercise on protein synthesis and myosin heavy chain gene expression in hypothyroid rats. Am J Physiol. 1994;267:E63-7.
28. Saadane N, Alpert L, Chalifour LE. Expression of immediate early genes, GATA-4, and Nkx-2.5 in adrenergic-induced cardiac hypertrophy and during regression in adult mice. Br J Pharmacol. 1999;127: 1165-76.

29. Suzuki J, Ohno I, Nawata J, Miura S, Ikeda J, Shirato K. Overexpression of insulin-like growth factor-I in hearts of rats with isoproterenolinduced cardiac hypertrophy. J Cardiovasc Pharmacol. 1999;34:635-44.

30. Schrader H, Krogness K, Aakvaag A, Sortland O, Purvis K. Changes of pituitary hormones in brain death. Acta Neurochir (Wien). 1980; 52:239-48.

31. Novitzky D, Cooper DK, Morrell D, Isaacs S. Change from aerobic to anaerobic metabolism after brain death, and reversal following triiodothyronine therapy. Transplantation. 1988;45:32-6.

32. Iwai A, Sakano T, Uenishi M, Sugimoto H, Yoshioka T, Sugimoto T. Effects of vasopressin and catecholamines on the maintenance of circulatory stability in brain-dead patients. Transplantation. 1989;48: 613-7.

\begin{abstract}
Online-www.aats.org
Now you can get The Journal of Thoracic and Cardiovascular Surgery online. The Journal online brings you faster delivery time, easy searching of current and back issues, links to PubMed, AATS, WTSA, and other important sites, and more. Visit the Journal online today.
\end{abstract}

\title{
Receive tables of contents by e-mail
}

To receive the tables of contents by e-mail, sign up through our Web site at http://www.mosby.com/jtcvs

Choose E-mail Notification

Simply type your e-mail address in the box and click the Subscribe button.

Alternatively, you may send an e-mail message to majordomo@mosby.com.

Leave the subject line blank and type the following as the body of your message: subscribe jtcvs_toc

You will receive an e-mail to confirm that you have been added to the mailing list.

Note that TOC e-mails will be sent out when a new issue is posted to the Web site. 